\title{
Passive containment cooling system with hydrogen recombiner for prolonged station blackout
}

\author{
Shripad T. Revankar \\ School of Nuclear Engineering, \\ Purdue University, \\ West Lafayette, IN 47907, USA \\ and \\ Division of Advanced Nuclear Engineering, \\ POSTECH, Pohang, 790-784, South Korea \\ Email:shripad@purdue.edu \\ Email: raknaver@gmail.com
}

\begin{abstract}
Beyond design basis accident scenario, where station blackout could lead to severe accident with hydrogen release, has become important after accident at Fukushima Daiichi nuclear plant. Here a passive containment cooling system (PCCS) combined with hydrogen mitigation system is suggested that will passively remove containment heat load as well as mitigate hydrogen gas generated and accumulated in the containment atmosphere during prolonged station blackout. It is proposed to make use of atmosphereic air as ultimate heat sink to reject the PCCS heat, which in turn transfers heat from the containment. In the proposed design a finned vertical tube type PCCS system submersed in pool water is considered with supply of pool water lasting three days following which airflow cools PCCS tubes for long term. The PCCS inlet flow path has a catalytic recombiner that is effective during first few days should there be any hydrogen generation and accumulation in the containment.
\end{abstract}

Keywords: passive containment cooling; passive condenser; severe accident; station blackout; hydrogen mitigation.

Reference to this paper should be made as follows: Revankar, S.T. (2019) 'Passive containment cooling system with hydrogen recombiner for prolonged station blackout', Int. J. Nuclear Safety and Security, Vol. 1, No. 1, pp.1-17.

Biographical notes: Shripad T. Revankar is a Professor of nuclear engineering and Director of the Multiphase and Fuel Cell Research Laboratory in the School of Nuclear Engineering at Purdue University. He is also BK 21st Visiting Professor at Pohang University of Science and Technology in the Division of Advanced Nuclear Engineering in South Korea. His research interests are in the areas of nuclear reactor thermal hydraulics and safety, multiphase heat transfer, multiphase flow in porous media, instrumentation and measurement, fuel cell design, simulation and power systems, and nuclear hydrogen generation.

This paper is a revised and expanded version of a paper entitled 'Passive hydrogen mitigation and cooling system for containment systems during prolonged station' presented at the '18th Pacific Basin Nuclear Conference (PBNC 2012)', BEXCO, Busan, Korea, 18-23 March 2012. 


\section{Introduction}

On 11 March 2011 at 2:46 pm, nuclear reactor plants at Fuksuhsima Daichii station in Japan experienced major accidents as a result of earthquake with magnitude around 9.0 followed by devastating tsunami.

These events have brought the world's attention to reactor safety during station blackout scenario. Four of the Fukushima Daiichi units, units 1, 2, 3 and 4 were badly affected by the accident. Seismically induced loss of offsite power and the failure of emergency power as a direct consequence of the tsunami triggered by the earthquake (TEPCO, 2011) resulted in failure of the core cooling in units 1,2 and 3. The emergency core cooling systems for these units relied mainly on active systems with AC and or DC power to operate them. The failure of the active systems resulted in a severe accident with hydrogen release from the core to the containment, hydrogen explosions and containment pressurisation. If passive systems did not rely on $\mathrm{AC}$ or $\mathrm{DC}$ power for cooling of reactor core and containment, the severity of the accident could have been smaller or totally avoided. In view of this, a passive containment cooling system combined with hydrogen mitigation system is suggested that will passively remove containment heat load as well as mitigate hydrogen from the containment atmosphere. Passive containment cooling system (PCCS) is one of the engineered safety systems in the advanced light water reactor. It is composed of either a shell and tube heat exchanger such as the Passive Containment Cooling System (PCCS) or an external air cooling system under various accident conditions to remove the energy out of the containment by natural circulation and condensation heat transfer. Passive autocatalytic recombiners have been proposed in the past to mitigate hydrogen in the containment. In this paper, first, a review of the worldwide efforts on experimental and modeling studies on PCCS is presented. The passive catalytic recombiner systems are coupled to the PCCS inlet. A novel finned tube PCCS condenser with hydrogen recombiner system is introduced and its possible implementation in light water reactor (LWR) is discussed.

\section{Passive containment cooling system}

\subsection{Passive containment cooling methods}

The reactor containment is the final barrier against the release of radioactive materials into the environment during a postulated reactor accident. So, the integrity of the containment system should be maintained during any postulated accident. This is done mainly by suppressing the pressure and temperature of the containment atmosphere below the design limits. In order to keep the integrity of the containment, reliable pressure suppression and containment cooling systems are required. The containment load comes from the released steam from the primary coolant system due to the loss of coolant accident (LOCA) or venting of the pressure relief valves. The major purpose of these containment cooling systems is to protect the containment under both Design Basis Accidents (DBAs) and severe accidents involving serious core damages and to prevent the significant release of radioactive materials to the atmosphere. The current boiling water reactors (BWR) have the containment pressure suppression pools where steam can be condensed. The suppression pool has limited water supply inside the containment and for long term decay heat removal, heat exchanger based reactor heat removal (RHR) 
systems are used. These RHR are based on active systems and are prone to fail as recent events at the Fukushima Daiichi nuclear power plants have clearly shown. Hence passive containment cooling systems are desirable. In fact, in recent designs of advanced LWR ESBWR the advanced BWR, and AP1000, the advanced pressurised water reactors (PWRs), have respectively PCCS (GE-NE 1992, 2006) and passive containment spray systems (Sha et al., 2006; IAEA, 2009).

The passive containment spray system uses natural draft air cooled containment. Subsequent to a LOCA, steam in contact with the inside surface of the steel containment is condensed. Heat is transferred through the containment wall to the external air. An elevated pool situated on top of the containment provides a gravity driven spray of cold water to provide cooling early in a LOCA scenario.

The PCCS system consists of either shell or tube heat exchangers with vertical or horizontal tubes with elevated pool as a heat sink. Steam vented in the containment condenses on the condenser tube outer or inner surfaces to provide pressure suppression and containment cooling. A water pool external to containment space or external air cooling system will remove the PCCS transferred heat energy out of the containment by natural circulation and condensation heat transfer under various accident conditions. The major part of the non-condensable (NC) gases consists of the original containment atmosphere such as air or nitrogen, however with the core damage, hydrogen or fission gases can also be released into the containment atmosphere. The thermal-hydraulic phenomena of importance are tube surface condensation with $\mathrm{NC}$ gases, natural circulation of steam and $\mathrm{NC}$ gases, degradation of condensation by the accumulation of $\mathrm{NC}$ gases and purging of $\mathrm{NC}$ gases from condenser systems.

\subsection{Vertical PCCS condenser (GE's SBWR/ESBWR)}

The Simplified Boiling Water Reactor (SBWR) (GE-NE, 1992) and Economic SBWR (ESBWR) (GE-NE, 2006) developed by General Electric (GE) were designed to employ a PCCS as shown in Figure 1. The PCCS is a system that passively removes heat from the containment to the liquid pool surrounding the PCCS heat exchangers (Dreier et al., 1999; Huggenberger et al., 1999).

The application of the PCCS to the nuclear power plant design was first proposed by GE for the SBWR design, where the PCCS is used not only to cool the containment but also to provide condensed water to the core through the Gravity-Driven Cooling System (GDCS). The GE's PCCS utilises the heat exchanger that consists of straight vertical heat transfer tubes having a relatively large diameter of $\sim 50 \mathrm{~mm}$, and large header pipes at the inlet and outlet of the tubes. The inlet header of the heat exchanger is connected to the Drywell (DW), and the outlet header is connected to the GDCS for the safety injection, and the Suppression Pool (SP) for the NC gas vent. This configuration enables the passive core cooling without dependence on active components for up to three days without operator intervention and thus is a very reliable system.

\subsection{Horizontal PCCS condenser (ABWR-II, Japan)}

The other type of the PCCS was proposed by the Japanese industries for the ABWR-II. For this design concept, the PCCS has only a function of the heat removal from the containment during severe accidents with failures of the active safety systems. In this concept the PCCS heat exchanger is connected to the DW for the inlet side and the SP for 
the outlet side (Kondo et al., 2006). Liquid water is supplied to the containment bottom region from the suppression chamber using some accident management measures in case that the core melt is ejected from the pressure vessel.

Figure 1 Schematic of ESBWR passive safety components (GE-NE, 2006)

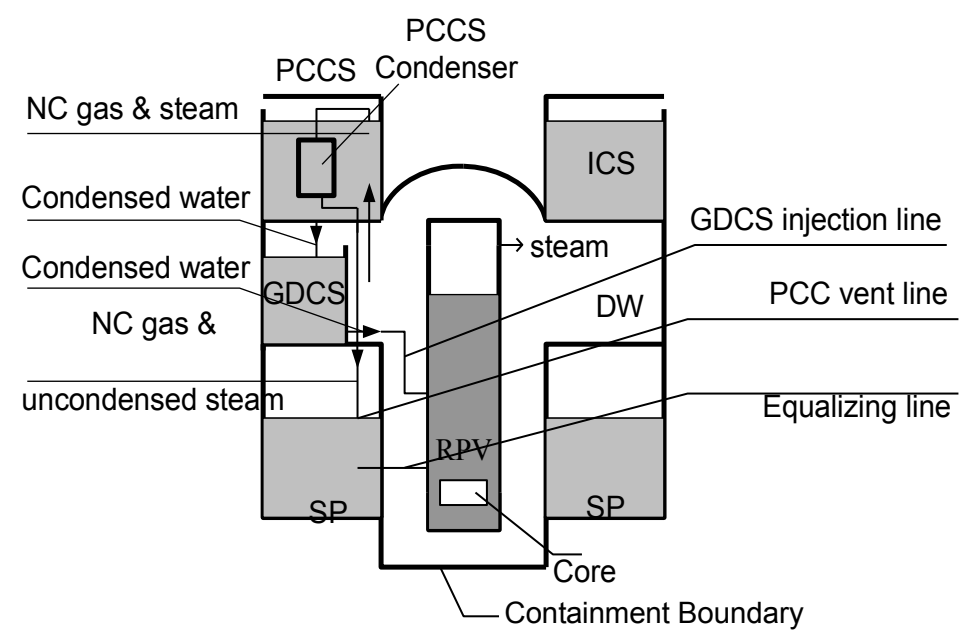

\subsection{External air cooling system (Westinghouse's AP600/AP1000)}

The AP600 and AP1000, advanced pressurised water reactors developed by Westinghouse, utilise an external air cooling aided by liquid spray to remove heat released from the containment vessel following postulated DBA (Sha et al., 2004). During a DBA, the steel containment vessel located inside the concrete shield building provides the heat transfer surface that removes heat from inside the containment and rejects it to the atmosphere. Heat is removed from the containment vessel by the continuous natural circulation of air within the shield building/containment vessel annulus. The air cooling is supplemented by evaporation of water. This cooling water drains by gravity from a tank located on top of the containment shield building. The water runs down over the steel containment vessel, thereby enhancing heat transfer. This passive containment cooling system design eliminates the safety-grade containment spray and fan coolers required for a conventional plant. The AP600 PCCS is designed to maintain containment pressure below the design limit for 72 hours without operator action during a DBA.

\section{PCCS studies and heat transfer relations}

\subsection{PCCS operational mode}

Three different operational modes are possible in the PCCS depending on the noncondensable gas concentration and the pressure difference between the DW and the SP. These are bypass or through flow mode, complete condensation mode, and cyclic venting mode (Revankar and Oh, 2003; Revankar et al., 2008). 
The PCCS is in through flow mode when the pressure difference between the DW and the SP is relatively high compared with the head due to the submergence of the vent line in the SP. This condition is realised during the blowdown process. In this mode, steam and non-condensable gas pass through the PCCS condensers with condensation. This mode of operation corresponds to forced convection flow condensation studied by Siddique et al. (1993) and Kuhn et al. (1997). When the pressure difference between the DW and the SP is comparable with the head due to the submergence of the vent line in the SP, the PCCS is in either complete condensation mode or cyclic venting mode depending on the non-condensable gas concentration. The PCCS is in complete condensation mode when the non-condensable gas concentration is very low. This condition is obtained in the later stage of an accidental transient after most of noncondensable gas is vented to the SP.

The PCCS is in cyclic venting mode when the non-condensable gas concentration is relatively high. This condition sets in immediately after the blowdown process. In this mode, steam has enough time to be condensed in the PCCS condensers. In the condensation process, non-condensable gas is accumulated in the PCCS condensers. Hence the DW pressure begins to rise as the condensation decreases. The DW pressure continues to increase after the condensation process greatly deteriorates. When the pressure difference is high enough to overcome the head due to submergence of the vent line in the SP, non-condensable gas is vented to the SP. The condensation process begins again after clearing of non-condensable gas from the PCCS. This cycle repeats. The effectiveness of clearing of the non-condensable gas from the PCCS tubes depends on the type of non-condensable gas. If hydrogen is present, then it accumulates in the top side of the condenser tube and may not clear from the tube during the venting process. The schematic of three operation modes is shown in Figure 2.

Figure 2 Three modes of PCCS operation; through flow showing continuous venting in SP, complete condensation show no venting to SP, and cyclic venting showing cyclic process of venting to no venting and back to venting

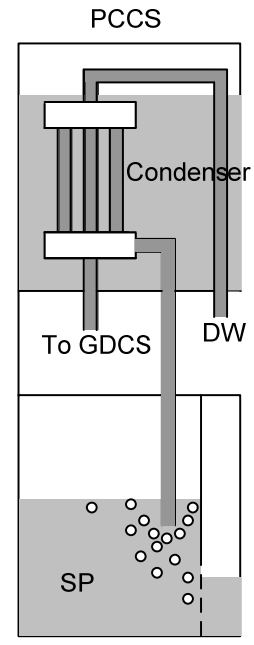

Through Flow

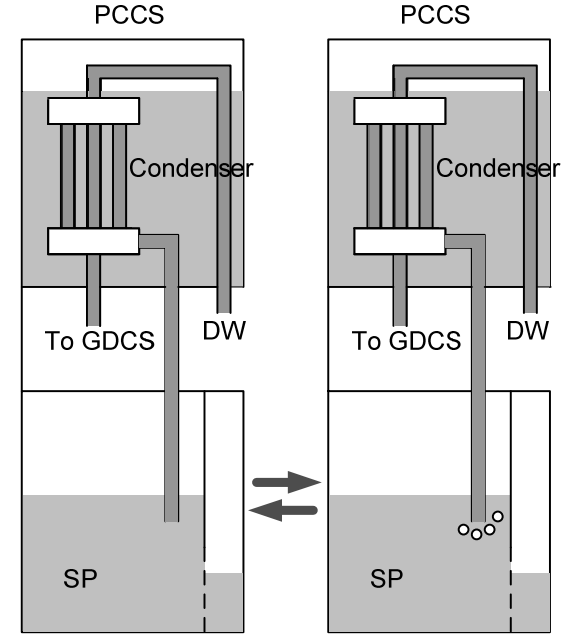

Cyclic Venting

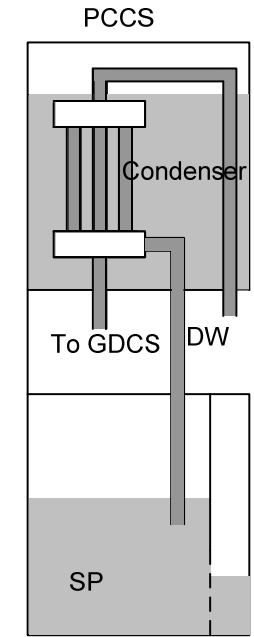

Complete Condensation 
Table 1 Previous vertical tube condensation separate effect experiments

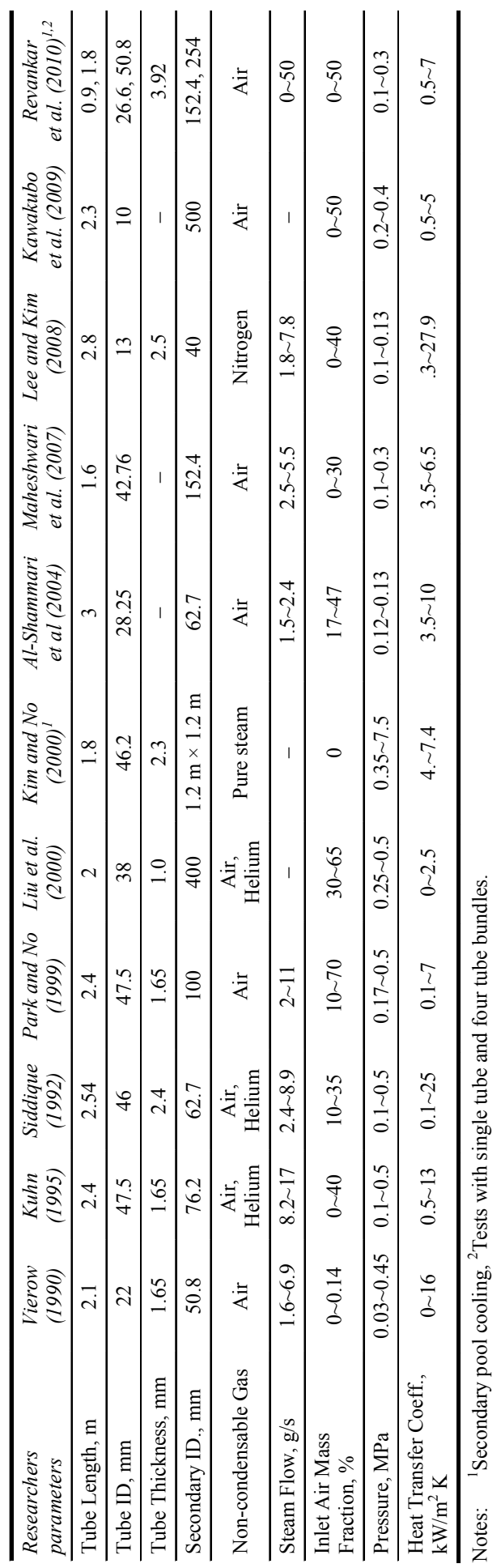




\subsection{Separate effects tests}

Since the work of Uchaida et al. (1964) which provided the first practical correlation for degradation of condensation from $\mathrm{NC}$ gas from experiments with steam-gas condensation on vertical wall, there is substantial amount of experimental work done related to PCCS condensation of steam inside a vertical tube in the presence of $\mathrm{NC}$ gas. Table 1 summarises the previous condensation experiments in a vertical tube for PCCS condensers proposed by the previous researchers for PCCS condenser.

\subsection{Integral tests}

The GIRAFFE (Vierow, 1993) test facility with a full-height and 1/400 reduced-volume was used by the Toshiba Corporation to investigate the thermal-hydraulic characteristics of the SBWR passive heat removal safety systems, support SBWR design certification in the USA, and support TRACG code qualifications. Both separate effects and system response tests were performed in order to investigate the ability of the PCCS heat exchanger tubes to condense steam in the presence of $\mathrm{NC}$ gases, demonstrate venting of the NC gases from the tube to the SP, and simulate the Main Steam Line Break (MSLB), Bottom Drain Line Break (BDLB), and GDCS Drain Line Break (GDLB) events. There was also a test to demonstrate the operation of the PCCS in the presence of lighter-thansteam NC gas.

The PANDA (Yadigaroglu, 1997) test facility is located at the Paul Scherrer Institute (PSI) in Switzerland and it is used to study the long term SBWR PCCS performance. It is a full height and 1/25 volume and power scale. A series of steady-state test were conducted using one of the PANDA PCC condensers with variations in air flow with a constant steam flow. Three tests were performed to investigate the effects of the PCCS pool inventory on system performance. Additional tests were run to investigate the PCCS start-up and long-term heat removal capabilities.

PANTHERS (Parlatan et al., 1996) is a test facility located at Società Informazioni Esperienze Termoidrauliche (SIET) in Italy, to provide data for TRACG qualification and to demonstrate testing of the performance of prototypic PCCS heat exchangers. The facility has full-size prototypic heat exchangers including a single condenser unit with two modules, each module having 248 tubes. Steam and NC gas were supplied to prototype heat exchangers over the complete range of SBWR conditions. A series of experiments were performed at the same thermal hydraulic conditions as in GIRAFFE and PANDA. The tests were conducted with low and high NC gas concentrations.

The PUMA (Ishii et al., 1996) test facility was built to simulate SBWR safety systems and obtain confirmatory integral test data for the U.S. Nuclear Regulatory Commission (NRC). Neither GIRAFFE nor PANDA contain all of the properly scaled engineered safety and safety grade systems in one facility, and hence cannot test the parallel operation of the safety systems. The U.S. NRC has identified a need to develop independent confirmatory data from a well-scaled integral test facility built to reproduce the major thermal-hydraulic phenomena at low pressure $(<1033 \mathrm{kPa})$. The PUMA facility has a scale of $1 / 4$ in height, $1 / 400$ in volume, and a time scale of $1 / 2$. The power is scaled by $1 / 200$ of the prototype and the pressure is scaled 1:1. The facility contains all of the important safety and non-safety systems of the SBWR that are pertinent to the postulated LOCA transients. The system response tests were performed such as MSLB, BDLB and GDLB and separate effect test has been carried out in order to investigate the ability of 
the PCCS heat exchanger tubes to condense steam in the presence of $\mathrm{NC}$ gases during the three operational modes of the PCCS, namely bypass, cyclic venting, and long-term cooling modes. Integral PCCS tests have also been carried out at LSTF integral test facility (The ROSA-V Group, 2003) for various small break LOCA.

\subsection{Key integral and separate effects test data}

For the long-term cooling mode, that is when PCCS is in complete condensation mode, the experimental data showed (Revankar et al., 2010) in that the effects of the DW pressure and the water level of the PCCS pool. As the DW pressure increases, the average heat removal rate also increases. For the bypass mode, the experimental results demonstrated the effects of the DW pressure and NC gas concentration. As the DW pressure increases, the average heat removal rate increases, while the average heat transfer coefficient decreases. Test results also showed that the average heat transfer coefficient decreases as the NC gas concentration increases in the PCCS. For the cyclic venting mode, the parametric effects on the heat transfer rate and heat transfer coefficient are the same as the long-term cooling and bypass modes. The PUMA-PCCS condensation heat transfer coefficients were compared with Kuhn's (1995) and Vierow's (1991) models and data from Purdue separate effects tests (Revankar et al., 2008b, 2010) as shown in Figure 3. The separate test data of Revankar et al. (2008b, 2010) cover the rest of the databank on PCCS condensation for all three modes of PCCS operation.

Figure 3 Key data comparison on effect of NC gas mass fraction on PCCS condensation heat transfer coefficient (HTC) for bypass and cyclic venting modes

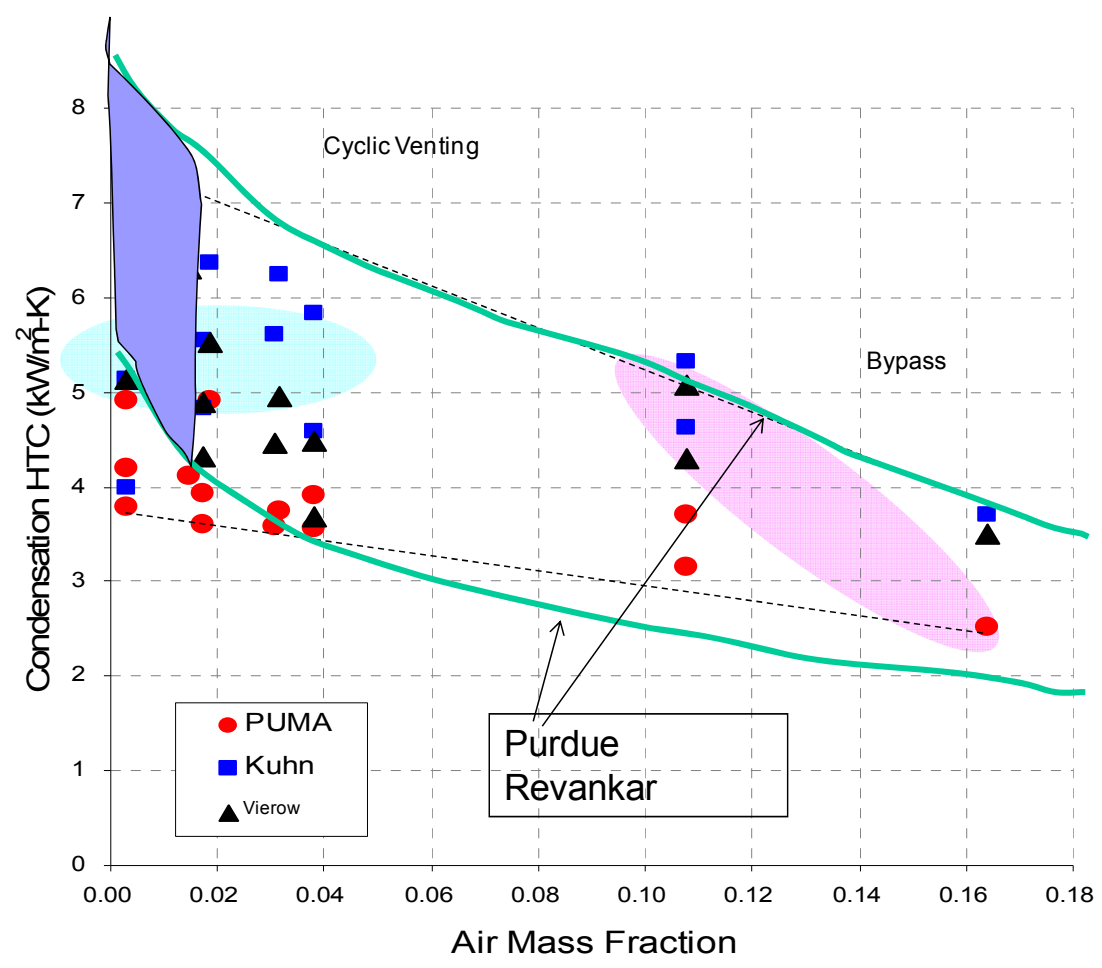




\subsection{Condensation heat transfer correlations}

There are two types of correlations for estimating the heat transfer coefficient for condensation inside vertical tubes. In first type of correlations, the local heat transfer coefficient is expressed in the form of a degradation factor defined as the ratio of the experimental heat transfer coefficient (when non-condensable gas is present) and pure steam heat transfer coefficient. The correlations in general are functions of local noncondensable gas mass fraction and mixture Reynolds number (or condensate Reynolds number). In the other type of correlation, the local heat transfer coefficient is expressed in the form of dimensionless numbers. In these correlations, local Nusselt number is expressed as a function of mixture Reynolds number, Jacob number, non-condensable gas mass fraction and condensate Reynolds number, etc. The degradation factor is defined as: $f=h_{\text {tot }} / h$, where $h_{\text {tot }}$ is the total heat transfer coefficient for the mixture of vapour and non-condensable and $h$ is the film condensation heat transfer coefficient for pure vapour. Here $f$ may be the function of film Reynolds number $\left(\operatorname{Re}_{f}\right)$, vapour/ non-condensable gas mixture Reynolds number $\left(\mathrm{Re}_{g}\right)$, non-condensable gas mass fraction $\left(W_{n c}\right)$, gas mixture Jacob number $\left(\mathrm{Ja}_{g}\right)$, Prandtl number $\left(\operatorname{Pr}_{g}\right)$.

Table 2 Degradation factor for condensation correlations in vertical tube with noncondensable gas and vapour mixture

\begin{tabular}{|c|c|}
\hline & Correlations based on degradation factor $f$ \\
\hline Authors & Empirical correlations \\
\hline $\begin{array}{l}\text { Vierow and } \\
\text { Schrock (1992) }\end{array}$ & $\begin{array}{rlrl}f=f_{1} \cdot f_{2} & =\left(1+2.88 \cdot 10^{-5} \cdot \operatorname{Re}_{g}^{1.18}\right) \cdot\left(1-c \cdot W_{n c}^{b}\right) \\
\text { where } \quad c & =10, & b=1.0 \quad \text { for } \quad W_{n c}<0.063 \\
c & =0.938, \quad b=0.13 \text { for } 0.063<W_{n c}<0.6 \\
c & =1.0, \quad b=0.22 \text { for } 0.6<W_{n c} .\end{array}$ \\
\hline $\begin{array}{l}\text { Kuhn et al. } \\
\text { (1997) }\end{array}$ & $\begin{array}{l}\text { For Air: } f=f_{1} f_{2}, f_{1}=f_{l_{-} \text {shear }}\left(1+7.32 \times 10^{-4} \mathrm{Re}_{f}\right), f_{l_{-} \text {shear }}=\frac{\delta_{N u}}{\delta_{\text {shear }}} \\
f_{2}=\left(1-2.601 W_{\text {air }}^{0.708}\right) \text { for } W_{\text {air }}<0.1 ; f_{2}=\left(1-W_{\text {air }}^{0.292}\right) \text { for } W_{\text {air }}>0.1 \\
\text { For Helium: } f=f_{1} f_{2} ; f_{1}=f_{l_{-} \text {shear }}\left(1+7.32 \times 10^{-4} \mathrm{Re}_{f}\right), f_{l_{-} \text {shear }}=\frac{\delta_{N u}}{\delta_{\text {shear }}} \\
f_{2}=\left(1-35.81 W_{H e}^{1.04}\right) ; \text { for } 0.003<W_{H e}<0.01, f_{2}=\left(1-W_{\text {air }}^{0.292}\right) \text { for } W_{\text {air }}>0.1 \\
f_{2}=\left(1-2.09 W_{H e}^{0.457}\right) \text { for } 0.01<W_{H e}<0.1 ; f_{2}=\left(1-W_{H e}^{0.137}\right) \text { for } W_{H e}>0.1 \\
f_{1_{-} \text {shear }}-\text { ratio of liquid film thickness with interfacial shear to film thickness } \\
\text { without interfacial shear, Re } e_{f}-\text { film Reynolds number, } W_{\text {air }}-\text { air mass } \\
\text { fraction, } W_{H e}-\text { helium mass fraction }\end{array}$ \\
\hline $\begin{array}{l}\text { Park and No } \\
\text { (1999) }\end{array}$ & $\begin{array}{l}f=0.0012 W_{n c}^{-1.4} J a^{-0.63} \operatorname{Re}_{f}^{0.24} \\
\text { for } 1715<\operatorname{Re}_{g}<21670,12.4<\operatorname{Re}_{f}<633.6, \quad 0.83<\operatorname{Pr}_{g}<1.04 \text {, } \\
0.111<W_{n c}<0.836, \quad 0.01654<\mathrm{Ja}<0.07351\end{array}$ \\
\hline
\end{tabular}


In Table 2, the degradation factors $f$ in the correlation for condensation heat transfer in vertical tube with non-condensable gas by various investigators are presented. In Table 3 condensation correlation based on non-dimensional parameters are presented that are applicable to vertical tube condensation with non-condensable gas and PCCS condenser. The correlations by Araki et al and Oh and Revankar provide correlations for the film condensation heat transfer coefficients. The correlation by $\mathrm{Oh}$ and Revankar applies for both pure steam and steam and air mixtures. This correlation also applies to all operational modes of the PCCS: complete condensation mode, through flow mode and cyclic venting mode. All other correlations in Table 2 and 3 apply to through flow operation of the PCCS, as these correlations were obtained based on data on through flow only.

Table 3 Condensation correlations in vertical tube with non-condensable gas and vapour mixture

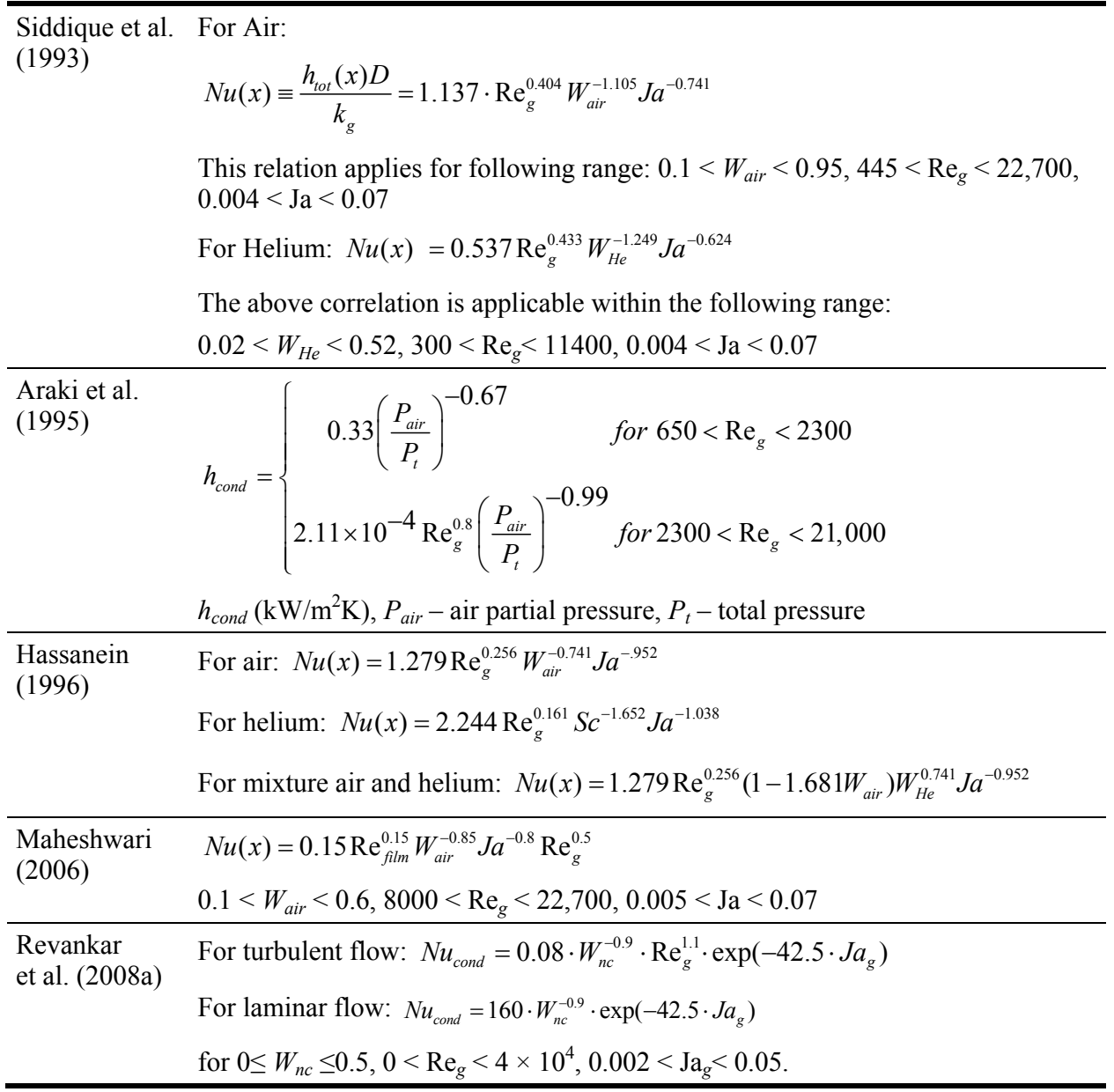




\section{Design of the passive hydrogen mitigation and containment cooling system}

The PCCS and hydrogen mitigation consists of (i) PHAR inlet and passive check valve, (ii) passive hydrogen autocatalytic recombiners (PHAR) (iii) PCCS/ICS pool with passive air inlet and steam/air exhaust, (iv) finned tube PCCS, and (iv) passive hydraulic check valve (PHCV). All these systems are based on passive activation and operation and just depend on gravity or pressure difference. These components do not require an electrical supply for activation or operation. Except for the check valve, none of these systems involves moving mechanical components and thus have very small probability of failure. Each of these components is described below. In Figure 4 the schematic of this system is illustrated.

Figure 4 Proposed design of passive hydrogen mitigation and containment cooling system

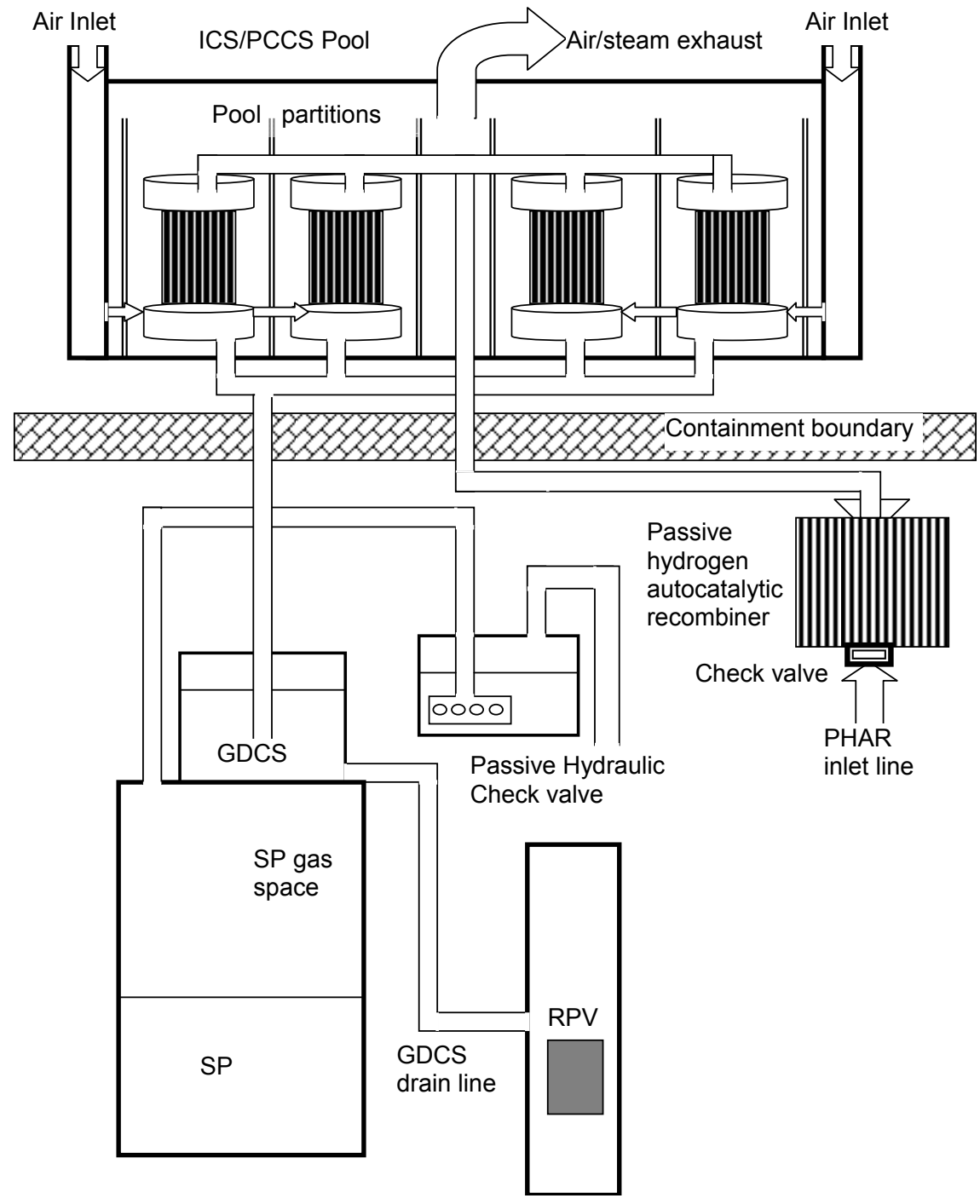




\subsection{PHAR inlet and passive check valve}

The inlet to the PHAR allows steam or gas to move through the PHAR and to the PCCS system. The inlets are located at the top of the drywall. The location of the inlets is designed such that all the top gas and steam accumulated near the top of the drywell can be exhausted through these lines through PHAR. The passive check valve designed is similar design as the vacuum breaker check valves in the ESBWR that connects between SP and DW. The reliability of this check valve has been demonstrated by General Electric to be fail proof with degree of reliability even if this valve leaks or fails to close it does not become a safety problem in this application.

\subsection{Passive hydrogen autocatalytic recombiners (PHAR)}

Typically a converter (housing) is used for directing gas flow through the PHAR from the bottom to the top. There are four such inlet locations on the top of the drywell each corresponding one each of PCCS system. The basic design specifications and the design of PHAR are typical for nuclear plant application (NUREG, 1998) and are given below.

(i) The hydrogen process of recombination should start at minimum hydrogen volume concentration depending on the steam and gas temperature: (a) no more than $2 \%$ at less than $100^{\circ} \mathrm{C}$, (b) no more than $1 \%$ at more than $100^{\circ} \mathrm{C}$. (ii) The process of recombination starts at minimal volume oxygen concentration no less than $2 \%$ flameless autocatalytic hydrogen recombination operates under volume hydrogen concentrations from $4 \%$ to $95 \%$. (iii) The time of the PHAR starting operation depending on the steam and water mixture temperature is: (c) no more than 10 minutes at less than $100^{\circ} \mathrm{C}$, (d) no more than $1 \mathrm{~min}$ at more than $100^{\circ} \mathrm{C}$. A catalyst module is a removable cassette, in which there is the material with autocatalytic covering. The PHAR gas mixtures containing hydrogen recombines in the presence of catalyst. Heat evolution during this reaction decreases gas density in the bottom of a recombiner and induce convection, providing high efficiency. The autocatalytic covering is hydrophobic and thermostable, that provides effective and long work (Blanchat and Malliakos, 2000). The cassette construction allows to take out the material with autocatalytic covering for performing tests. PHAR are oriented on maximum pressure differential, arising out of various operation modes and nuclear plant accidents. PHAR are oriented on seismic activity during design earthquakes and MRA (maximum rated earthquakes). Typical lifetime of the PHAR is 30 years and the troublefree life is 8 years. The lifetime of the PHAR autocatalytic modules is 5 years. General maintenance is every 5 years. Regenerating time is no more than $50 \mathrm{hr}$ (Eckardt and Losch, 2000).

The proposed autocatalytic catalytic recombiner has unique function for prolonged station blackout situation as there is possibility of oxygen accumulation which may have been released due to radiolysis or leakage from axillary containment building. The function of autocatalytic catalytic recombiner is primarily to initiate hydrogen oxidation if there is oxygen presence in drywell space. If there is no oxygen in the drywell the hydrogen gas just behaves like inert gas and has no safety implication other that it is a non-condensable gas that affects the condensation of PCCS. But after venting it through PCCS it will accumulate is SP gas space. The autocatalytic catalytic recombiner makes sure there is no issue with drywell hydrogen problem for prolonged station blackout. 


\subsection{PCCS/ICS pool with passive air inlet and steam/air exhaust}

The ICS and PCCS pool with partitions for individual condenser units provides 2-3 days of water for cooling and heat sink to the PCCS and ICS condenser and the design is similar to the ESBWR ICS/PCCS pool (GE-NE, 2006), except that the pool has air draft column where atmosphere air can flow into the pool space when the pool water is evaporated. The partitions are each connected with vents at the bottom of the pool so that air distributes between various partitions. The exhaust from the pool is directly vented to the atmosphere. The water inventory in the pool provides the heat sink to the condenser for first two-three days. Then once the water is exhausted, the atmospheric air will move into the pool and provides cooling to the condensers for long period operation. The motion of the air is driven due to net air density difference between the inlet and outlet of the pool. The concept is similar to the air cooling adapted in AP1000 reactor containment cooling.

\subsection{Finned tube PCCS}

The condenser design is similar to the ESBW condenser except that the tube will have fins to provide large surface area for the cooling. The fins on the surface provide high efficiency cooling to the condenser with water during initial period and then for long term cooling with air is very effective. At later period the decay heat levels are low and the design of the PCCS capacity is based on the maximum heat removal ability of the finned tube PCCS condenser after water is boiled from the pool.

\subsection{Passive hydraulic check valve (PHCV)}

This check valve designed has similar function as vacuum breaker check valves in the ESBWR that connects between SP and DW. The design is based on the design of the hydraulic vacuum breaker check valve proposed by Yoon et al. (2006). The principle of operation of the PHCV is based on the free surface of the gas liquid system and the hydrostatic head. There is a passive system with no moving part in this design. The design of the PHCV consists of a water tank and two ports connecting to the gas space of the SP and the DW space. The inlet piping to the PHCV is immersed in the tank water with the water level providing the required head for the flow to commence from SP to the DW. This design has advantage that variation in the water level changes the differential pressure required for the flow to ensue.

To implement this new design in the prototype reactor containment, the following issues are considered. (1) First, if the outlet side pressure is higher (DW) than the inlet side (SP gas space), then the water rises through the submersed piping to the inlet side. This will in effect reduce the tank water level if the water surface area is smaller. Also if the inlet piping is too short, then the water from the tank drains in to the SP and thus will fail to provide any hydrostatic head. In order to avoid these problems, a sufficient height to the inlet piping is provided. The vertical height of the pipe is such that the hydrostatic head associated with the vertical length is larger than the possible maximum pressure difference between the DW and SP. This prevents overflow of the water from the tank to the inlet side. Also, the surface area of the water in the tank is large such that the water rise in the vertical pipe does not change the water level by more than $1 \%$. (2) Since the inlet flow introduces bubbles or gas jet in the tank water, there may be carry-over of the 
entrained droplets to the DW. In order to eliminate the droplet carry over, the venting flow area of the submersed pipe should be large. A sparger design is included in the submerged pipe end to reduce the vent gas velocity close to the bubble rise velocity. (3) Since the PHCV valve system is connected to the DW atmosphere through piping, there is the possibility of continuous evaporation of the water into the DW atmosphere. In order to avoid this problem a $90^{\circ}$ pipe bend is provided and the end of the pipe is at the tank water level. This arrangement minimises escape of water vapour by mass diffusion from the tank to the DW by reducing the concentration gradient.

As shown in Figure 4, the schematic design of the PHCV valve is shown for application in the reactor system. The valve system consists of a horizontal water tank that will be placed in the DW space. This tank has two pipe connections. The first pipe connects to the DW with an inverted U bend. The second pipe connects the SP gas space. The pipe from SP has the sparger, which is submerged in the tank water. The vertical inverted bend in the pipe is introduced to reduce the natural circulation motion of moisture or gas in the pipe as described above. The water head above the sparger level determines the pressure difference required for venting of the gas from the DW to the PCCS.

\section{Conclusions}

There are three PCCS condensation operational modes, bypass mode, cyclic mode and complete condensation mode that depend on the stage of the accident. For long term cooling the cyclic venting and complete condensation modes are relevant. Hence the vacuum breaker check valve and the PCCS operation are important for long term cooling. The existing work on the integral tests and the modelling effort on the PCCS was reviewed highlighting the effect of non-condensable on heat transfer rate of the PCCS. The relevant correlations for PCCS condensations were presented. The correlation developed at Purdue University applies for all modes of PCCS condensation and has been tested with other separate effects tests data. Thus there is a considerable understating on the heat transfer characteristics of the PCCS system for application to LWR.

Current design for the PCCS heat sink is based on pool water. However for extended period of PCCS cooling this poses limitation. Hence for extended period it is proposed to atmosphere air as ultimate heat sink to reject the PCCS heat which in turn transfers heat from the containment. Passive hydrogen autocatalytic recombiners have been proposed for use in the containment. In the proposed design finned vertical tube type PCCS system submersed in pool is cooled for first 2-3 days with water. Once the water is boiled off atmospheric air is drawn to cool the PCCS tubes for long term. The PCCS inlet flow path has catalytic recombiner that is effective during first few days should there be any hydrogen generation and accumulation in the containment. The proposed PCCS and hydrogen mitigation system consists of PHAR with passive check valve, PHAR, PCCS/ICS pool with limited water supply and passive air inlet and steam/air exhaust, and filled tube PCCS. For the long reliable operation of PCCS passive hydraulic check valve is proposed that enables flow of gas from SP to drywell should the SP pressure increases above drywell pressure. All these systems are based on passive activation and operation and just depend on gravity or pressure difference. 


\section{References}

Al-Shammari, S.B., Webb, D.R. and Heggs, P. (2004) 'Condensation of steam with and without the presence of non-condensable gases in a vertical tube', Desalination, Vol. 169, No. 2, pp.151-160.

Araki, H., Kataoka, Y. and Murase, M., 1995, Measurement of condensation heat transfer coefficient inside a vertical tube in the presence of noncondensable gas', Journal Nuclear Science and Technology, Vol. 32, pp.78-91.

Blanchat, T.K. and Malliakos, A. (2000) 'Testing a passive autocatalytic recombiner in the Surtsey facility', Nuclear Technology, Vol. 129, pp.356-373.

Dreier, J., Aubert, C., Huggenberger, M., Strassberger, H.J., Meseth, J. and Yadigaroglu, G. (1999) 'The PANDA Tests for the SWR 1000 Passive Containment Cooling System', Proceedings of the 7th International Conference on Nuclear Engineering (ICONE-7), ICONE-7316, 19-23 April, Tokyo, Japan.

GE-NE (2006) 'ESBWR Design Control Document' Tier 2', Chapter 6, Engineered Safety Features, Doc No. 26A6642AT Edition, General Electric Nuclear Energy.

GE-NE (1992) SBWR Standard Safety Analysis Report, Report No. 25A5113, Rev. A General Electric Nuclear Energy, August.

Eckardt, B.A. and Losch, N. (2000) 'Passive autocatalytic recombiner systems: design, qualification and implementation', Proceedings of the 26th Annual SNE Meeting, 4-6 October, Leon, Spain.

Hassanein, H.A., Kazimi, M.S. and Golay, M.W. (1996) 'Forced convection in-tube steam condensation in presence of noncondensable gases', International Journal of Heat Mass Transfer, Vol. 39, pp.2625-2639.

Huggenberger, M., Aubert, C., Bandurski, Th., Dreier, J., Fischer, O., Strassberger, H.J. and Yadigaroglu, G. (1999) 'ESBWR related passive decay heat removal tests in PANDA', Proceedings of the 7th International Conference on Nuclear Engineering (ICONE-7), ICONE-7322, 19-23 April, Tokyo, Japan.

IAEA (2009) 'Passive safety systems and natural circulation in water cooled nuclear power plants', IAEA-TECDOC-1624, IAEA, Vienna.

Ishii, M., Revankar, S.T., Dowlati, R., Bertodano, M.L., Babelli, I., Wang, W., Pokharna, H., Ransom, V. H., Viskanta, R., Wilmarth, T. and Han, J.T. (1996) Scientific Design of Purdue University Multi-Dimensional Integral Test Assembly (PUMA) for GE SBWR, Purdue University PU-NE 94/1, NRC Technical Report, NUREG/CR-6309.

Kawakubo, M., Aritomi, M., Kikura, H. and Komeno, T. (2009) 'An experimental study on the cooling characteristics of passive containment cooling systems', Journal of Nuclear Science and Technology, Vol. 46, No. 4, pp.339-345.

Kim, S.J. and No, H.C. (2000) 'Turbulent film condensation of high pressure steam in a vertical tube', International Journal of Heat and Mass Transfer, Vol. 43, pp.4031-4042.

Kondo, M., Nakamura, H., Kukita, Y., Kurita, T., Arai, K., Okazaki, T. and Inoue, R. (2006) 'Primary-side two-phase flow and heat transfer characteristics of a horizontal-tube PCCS condenser', Proceedings of the 14th International Conference on Nuclear Engineering (ICONE-14), ICONE14-89652, July 17-20, Miami, FL, USA.

Kuhn, S.Z. (1995) Investigation of Heat Transfer from Condensing Steam-Gas Mixtures and Turbulent Films Flowing Downward Inside a Vertical Tube, PhD thesis, Department of Nuclear Engineering, University of California, Berkeley, CA.

Kuhn, S.Z., Schrock, V.E. and Peterson, P.F. (1997) 'An investigation of condensation from steamgas mixtures flowing downward inside a vertical tube', Nuclear Engineering and Design, Vol. 177, pp.53-69.

Lee, K.Y. and Kim, M.H. (2008) 'Experimental and empirical study of steam condensation heat transfer with a noncondensable gas in a small-diameter vertical tube', Nuclear Engineering and Design, Vol. 238, No. 12, pp.207-216. 
Liu H., Todreas, N.E. and Driscoll, M.J. (2000) 'An experimental investigation of a passive cooling unit for nuclear plant containment', Nuclear Engineering and Design, Vol. 199, pp.243-255.

Liu H., Todreas, N.E. and Driscoll, M.J. (2000) 'An experimental investigation of a passive cooling unit for nuclear power plant containment', Nuclear Engineering and Design, Vol. 199, pp.243-255.

Maheshwari, N.K. (2006) Studies on Passive Containment Cooling System of Indian Advanced Heavy Water Reactor, $\mathrm{PhD}$ thesis, Tokyo Institute of Technology, Tokyo, Japan.

Maheshwari, N.K., Vijayan P.K and D. Saha D. (2007) 'Effects of non-condensable gases on condensation heat transfer', 4th RCM on the IAEA CRP on Natural Circulation Phenomena, Modelling and Reliability of Passive Safety Systems that Utilize Natural Circulation, 10-13 September, Vienna, Austria.

NUREG (1998) Performance Testing of Passive Autocatalytic Recombiners, Report NUREG/CR6580, Sandia National Laboratory, June.

Park, H.S. and No, H.C. (1999) 'A condensation experiment in the presence of non-condensable in a vertical tube of a passive containment cooling system and its assessment with RELAP5/MOD3.2', Nuclear Technology, Vol. 127, No. 2, pp.160-168.

Parlatan, Y., Boyer, B.D., Jo, J. and Rohatgi, U.S. (1996) 'Analysis of PANTHERS full-scale heat transfer tests with RELAP5', Proceedings of the 4th International Conference on Nuclear Engineering (ICONE-4), 10-13 March, New Orleans, LA, USA.

Revankar, S.T. and Oh, S. (2003) Analytical and Experimental Study of The Effects of NonCondensable in a Passive Condenser System for the Advanced Boiling Water Reactor, Department of Energy, Technical Report, DE-FG07-00ID13928.

Revankar, S.T., Oh, O., Zhou, W. and Henderson, G. (2008a) 'Condensation correlation for a vertical passive condenser system', Proceedings of the International Congress on Advances in Nuclear Power Plants (ICAPP'08), 8-12 June, American Nuclear Society, ANS Annual Meeting, Anaheim, California, USA.

Revankar, S.T., Zhou, W. and Henderson, G. (2008b) Experimental and Thermalhydraulic Code Assessment of the Transient Behavior of the Passive Condenser System in an Advanced Boiling Water Reactor, DOE Report No. DOE/ID/14605, Purdue University School of Nuclear Engineering Report PU/NE-08-13.

Revankar, S.T., Zhou, W. and Henderson, G. (2010) Experimental and Model Analysis of Tube Bundle Experiments for Passive Condenser System in an Advanced Boiling Water Reactor, Report PU/NE-10-11, Purdue University School of Nuclear Engineering.

Sha, W.T., Chien, T.H., Sun, J.G. and Chao, B.T. (2004) 'Analysis of large-scale tests for AP-600 passive containment cooling system', Nuclear Engineering and Design, Vol. 232, pp.197-216.

Siddique, M. (1992) The Effects of Noncondensable Gases on Steam Condensation under Forced Convection Conditions, PhD Thesis, Department of Nuclear Engineering, Massachusetts Institute of Technology.

Siddique, M., Golay, M.W. and Kazimi, M.S. (1993) 'Local heat transfer coefficients for forced convection condensation of steam in a vertical tube in the presence of a non-condensable gas', Nuclear Technology, Vol. 102, pp.386-402.

TEPCO (2011) Press releases website. Available online at: http://www.tepco.co.jp/en/press/ corpcom/release/indexe.html

The ROSA-V Group (2003) ROSA-V Large Scale Test Facility (LSTF) System Description for the Third and Fourth Simulated Fuel Assemblies, JAERI-Tech 2003-037.

Uchida, H., Oyama, A. and Togo, Y. (1964) 'Evaluation of post-incident cooling systems of light water reactors', Proceedings of the 3rd International Conference on Peaceful Uses of Atomic Energy, Vienna, Austria, International Atomic Energy Agency, Vol. 13, pp.93-104. 
Vierow, K.M. (1990) Behavior of Steam-Air Systems Condensing in Concurrent Vertical Downflow, MS Thesis, Department of Nuclear Engineering, University of California at Berkeley, CA.

Vierow, K.M. and Schrock, V.E. (1991) 'Condensation in a natural circulation loop with noncondensable gases, part I - heat transfer', International Conference on Multiphase Flows, 24-27 September, Tsukuba, Japan, pp.183-186.

Vierow, K.M. (1993) GIRAFFE Passive Heat Removal Testing Program, Technical Report NEDC32215P, GE Proprietary Information.

Yadigaroglu, G. (1997) The PANDA Tests for the SBWR, 25th Water Reactor Safety Information Meeting, Bethesda, MD, USA.

Yoon, H.J., Revankar, S.T., Xu, Y. and Ishii, M. (2006) 'Design and test of hydraulic vacuum breaker check valve for simplified boiling water reactor', Nuclear Engineering and Design, Vol. 236, pp.2405-2410. 